\title{
ENGAGING YouTH IN LIFELONG Outdoor Adventure Activities through a Nontraditional Public School Physical Education Program
}

\author{
$K_{\text {ERI }} S_{C H W A B}$ \\ Daniel Dustin
}

\begin{abstract}
In 2007 Cavett Eaton, a master's student in parks, recreation, and tourism at the University of Utah, was struggling with how to foster enjoyment of outdoor activities in youth, how to enhance youth's understanding and appreciation of risk, and how to provide opportunities for youth to learn lifelong leisure activities. Stemming from his own childhood experiences, and reinforced by many years working as an environmental educator, Eaton had come to believe that participating in outdoor activities that included a measure of risk could help build positive character traits in youth, as well as cultivate their sense of wonder, curiosity, and respect for all living things.
\end{abstract}

Eaton had yet to figure out what setting, location, or infrastructure could support such a program, until he read an article in JOPERD by Dustin, McKenney, Hibbler, and Blitzer (2004). In the article "Thinking Outside the Box: Placing Park and Recreation Professionals in K-12 Schools," Dustin and his colleagues suggested hiring park and recreation professionals to work in the public schools, and then provided a strong rationale for doing so. To Eaton, the article justified what he had wanted to do for years. He now needed to find a willing partner to help him accomplish his goal. His timing was perfect, as he had just been approached about starting a new physical education program at the Salt Lake Center for Education (SLCSE), a 6th- to 12th-grade school district-sponsored charter school in Salt Lake City, Utah.

This article provides a brief review of the rationale put forth by Dustin et al. (2004) and a description of Eaton's nontraditional physical education and health program that was inspired by it, including Eaton's underlying conceptual foundation anchored in the ideas of conservationist Rachel Carson, journalist Richard Louv, and physician John Ratey. Selected elements of Eaton's program are then highlighted, illustrating a successful marriage of recreation, adventure, risk, choice, and freedom with the fitness requirements of a traditional physical education and heath curriculum.

\section{Thinking Outside the Box}

What resonated most with Eaton in the 2004 JOPERD article were the numerous ways park and recreation programming could complement the work of public school teachers. Capitalizing on these complementary features, he thought a public school would be the ideal place to find a captive audience to work on the traits and skills he found lacking among so many youth during his years as an environmental educator. While earning his teaching certification through the Alternative Route to Licensure program in Utah, Eaton continued to ponder the points raised in "Thinking Outside the Box."

Dustin and his colleagues described three ways that park and recreation professionals could complement the work being done by public school teachers. First, they stressed the importance of educating the whole child and understanding children's non-school environment. Knowing more about children's behaviors in recreation or other "free time" settings could provide insight into their personalities that might not be evident when confined to a desk in a classroom. This understanding could then help teachers better meet their students' educational needs. Second, the authors advocated for collaboration between teachers and park and recreation professionals to "understand and appreciate the mutually reinforcing qualities of a fully functioning mind and body" (Dustin et al., 2004, p. 53). Third, the authors noted that park and recreation professionals typically have strong interpersonal skills, honed during years of field experience, as well as in formal educational programs. Their understanding of and experience with relationship building, teamwork, group dynamics, and communication could come in handy in a public school setting.

Dustin et al. (2004) also offered several logistical reasons why public schools would be a prime location to support the kind of work Eaton had in mind (based on Crompton, 2000). First, school facilities are often underutilized, especially in the late afternoons and evenings, on weekends, and over summer break. This space would be ideal for recreation programs. Second, schools often run after-school programs, sometimes for tutoring or additional

Keri Schwab (keschwab@calpoly.edu) is an assistant professor in the Recreation, Parks, and Tourism Administration Department at California Polytechnic State University-San Luis Obispo in San Luis Obispo, CA. Daniel Dustin is a professor in the Department of Parks, Recreation, and Tourism at the University of Utah in Salt Lake City, UT 
academic help. But those programs could easily include a recreation component where children could get "hooked" on healthpromoting recreation activities. Indeed, rather than sending students to empty homes after school, recreation programs have been found to help keep children out of trouble during after-school hours (Schreffler, 2002).

Based on the JOPERD article, Eaton developed a clear and straightforward rationale for the inclusion of park and recreation professionals in the public schools, not just after school, but during school. Building on his experience as an environmental educator, equipped with a recently acquired master's degree in parks, recreation, and tourism, having begun the steps to acquire a Utah teaching license, and complemented by a personal passion for outdoor adventure recreation, Eaton pitched a nontraditional physical education curriculum to his school principal, Larry Madden. And Madden, a risk taker in his own right, took a leap of faith.

\section{Creating a Holistic Recreation and Physical Education Program}

Eaton knew his program would need a sound philosophical foundation to justify the outdoor adventure activities. He also knew that in Utah, his curriculum had to align with the State Core Curriculum Content Standards for physical education and health. With the support of his principal, Eaton implemented a "Healthy Lifestyles and Outdoor Explorations Skills" program that satisfied
Utah's requirements. In essence, the curriculum "hides" physical activity and character building in enjoyable, sustainable, lifelong leisure pursuits. Eaton also meets traditional physical education and health requirements by devoting two weeks of instruction to each of the major ball sports, including technique and game play instruction. Student physical fitness gains are also tracked by a Fitnessgram assessment administered three times a year, but overall, the focus is on healthy lifestyle development and character education.

In designing his program, Eaton drew inspiration from biologist and conservationist Rachel Carson (1998), journalist Richard Louv (2006), and physician John Ratey (2008). Carson taught him the importance of a sense of wonder in children because that wonder could be "an unfailing antidote against the boredom and disenchantment of later years, the sterile preoccupation with things that are artificial, the alienation from sources of our strength" (p. 54). Louv's Last Child in the Woods alerted him to the potential harm caused by a lack of exposure to the natural world. And Ratey's Spark: The Revolutionary New Science of Exercise and the Brain provided scientific support for the idea that physical activity could improve cognitive functioning and academic achievement scores.

Combining the logic contained in these three sources, Eaton built abundant opportunities in his physical education program to experience nature and to explore, question, wonder, and participate in outdoor activities. Determined that he wanted to educate the whole child - body and mind - Eaton aligned these ideas with

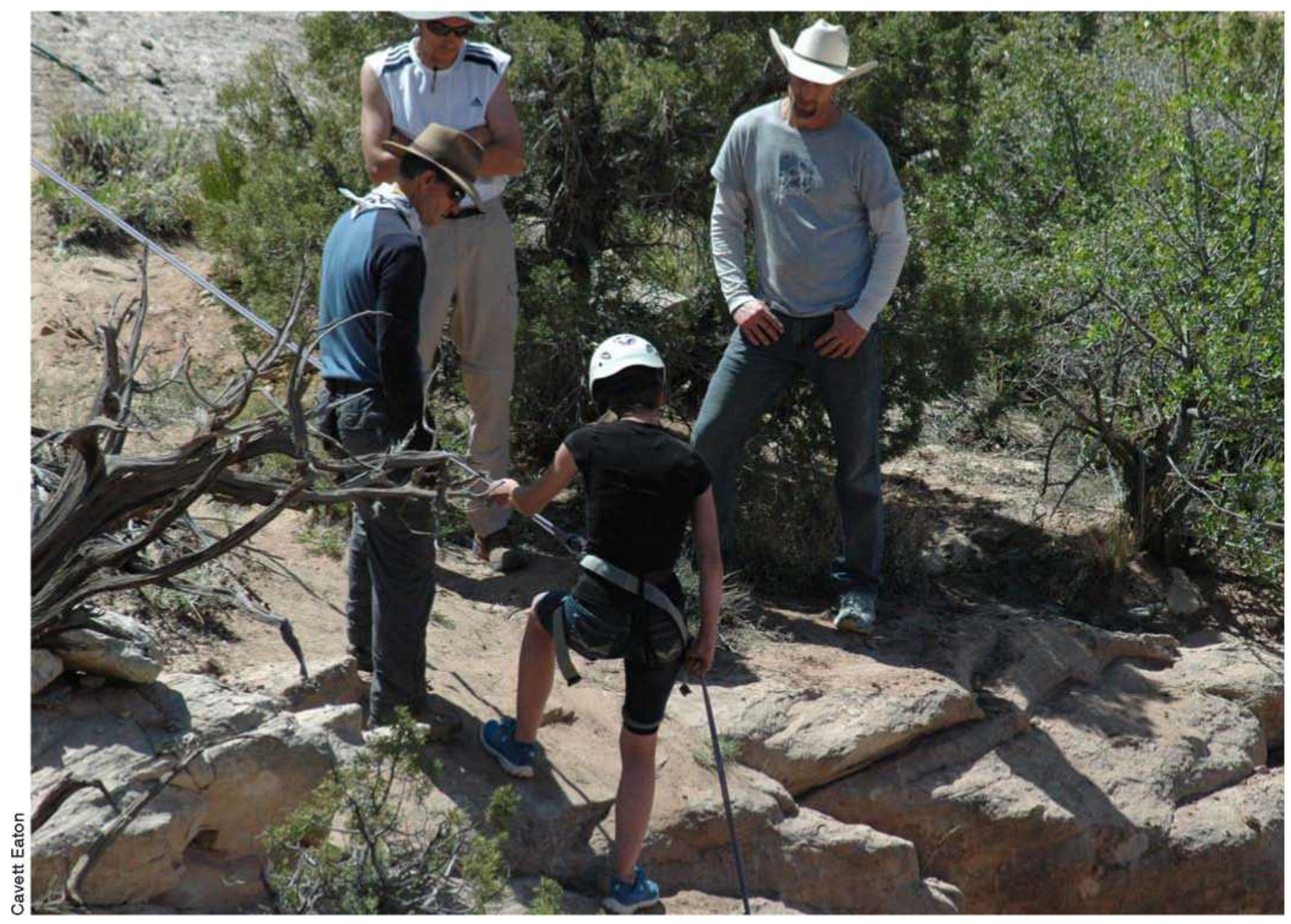




\section{Figure 1. Bike-shop class description}

\section{Course Description:}

This course will allow students to learn skills related to bicycle maintenance and repair in a context that promotes community service. The school "fleet" will be maintained in this course, students will have opportunities to work on their own bikes, and students will provide service to the community by working on bikes belonging to children in the neighborhood proximal to the school.

Course Outline:

- Bicycle history

- Bicycle safety

- Parts of a bicycle

- Maintenance and repair of bicycles

- The school "fleet"

- Bicycles in the community

Lessons and Activities:

Class activities consist of lessons on basic repair and maintenance such as how to repair an inner tube and change a flat tire, adjust or fix gears, and generally maintain the bike in safe working order. Outdoor lessons include how to prepare for a safe bike ride, basic bike-riding techniques such as proper body position and braking, and how to bike with traffic including proper hand signaling and defensive biking techniques. Built into each lesson are opportunities for problem-solving, decision-making, and taking personal responsibility for one's bike and related equipment.

the state physical education and health requirements and created a curriculum that "uses an outdoor adventure model with training and activities that challenge students with healthy risks and allow personal growth and development at their individual pace."

Hiding Physical Activity in Recreation. The beauty of the Healthy Lifestyles and Outdoor Exploration Skills program is that it keeps students physically active without them knowing it. Instead of typical physical conditioning exercises, SLCSE students improve their physical fitness by performing maintenance on bikes, riding or walking to school, slow-paddle kayaking in the nearby Jordan River and Great Salt Lake, snowshoeing, belaying a partner on the indoor ropes course, practicing indoor rock climbing or slack lining, and camping. To increase the amount of daily time students are physically active, Eaton offers before- and after-school sessions and several hugely popular weekend field trips each semester (overnight "training camps" in the school's sheltered courtyard and others in the nearby Wasatch mountains). The fitness component is largely hidden in a treasure chest of intrinsically rewarding experiences and often includes basic math and science lessons in collaboration with other SLCSE instructors.

These rewarding experiences are also designed to meet state and national standards for physical education and health. For example, National Standard 4 requires that students demonstrate respectful personal and social behaviors in a physical activity setting (SHAPE America - Society of Health and Physical Educators, 2014). Students can demonstrate this by following rules, making responsible choices that lead to safe actions, and not giving into peer pressure. Standard 5 requires that students understand the enjoyment, challenge, self-expression, and social interaction inherent in many physical activities (SHAPE America, 2014) and demonstrate their understanding of this by overcoming fears, showing consideration toward personal abilities and limitations, and participating in activities with students of various backgrounds and ability levels. Eaton's program engages students in group and solo activities in a variety of settings, which provides opportunities for students to practice these character traits.

Lifetime Activities. Eaton firmly believes that youth need to learn physical activities they can engage in for the rest of their lives. He chooses low-impact activities such as bicycling, kayaking, swimming, walking, hiking, camping, and slack lining because of their lifelong viability. They are activities youth can participate in alone or with others, and in a variety of settings. Moreover, the activities offer students the opportunity to engage in problem solving, critical thinking, and technical skill building. Each activity also has its own unique physical benefits, which address requirements in the Utah curriculum standards. For example, when slack lining, Eaton teaches the importance of good balance for healthy aging. When kayaking, Eaton stresses the meditative possibilities when floating downstream and the ability of nature to produce attention restoration. When snowshoeing, Eaton's students monitor their own heart rate, learn about the benefits of cardiovascular fitness, and better understand how to participate safely on cold, snowy days. When camping, Eaton teaches basic survival skills. Finally, along with their active involvement, Eaton teaches students how to maintain and repair their equipment. This is necessary, in part, because the equipment is often donated or used and in need of basic maintenance and care. Eaton turns this into an opportunity to learn responsibility for one's belongings and to acquire the technical care skills needed for lifetime participation. For example, Figure 1 describes a bike shop class in which students learn bicycle skills and safety, as well as bicycle maintenance and repair.

Lifetime Behaviors. There are many opportunities for learning "soft skills," or nontechnical skills, in Eaton's program. He often focuses on interpersonal relationships and building self-confidence. To facilitate such skill development, Eaton draws on his experiential education background to help hone his students' ability to make meaning of experiences and apply it to later life. Drawing on Kolb's (1984) experiential learning cycle, Eaton often asks students to reflect on what they did, what it meant, what they learned, and how to apply it later. During outdoor activities, for example, Eaton challenges his students to work together to make decisions and solve problems. After an activity is finished, he asks them what communication styles helped get them through the experience. Reflecting on the process can reveal specific ways in which the students worked through a situation and can prepare them for similar situations. Or, when challenged to the point of exhaustion, Eaton asks students if they are following their motto to "Do the right thing, and do your best work." If not, Eaton asks the students to reassess their attitude, the situation, and their relationships with one another, and then try again. In Eaton's mind, the experience of trying, and the ability to overcome challenges, are paramount to his students' success - not just in outdoor activities but also in later academic settings, careers, and relationships. This cultivation of self-reflection and a mindset of perseverance lead to attitudes and behaviors that will help Eaton's students succeed in their academic and personal lives well beyond the middle and high school years. 


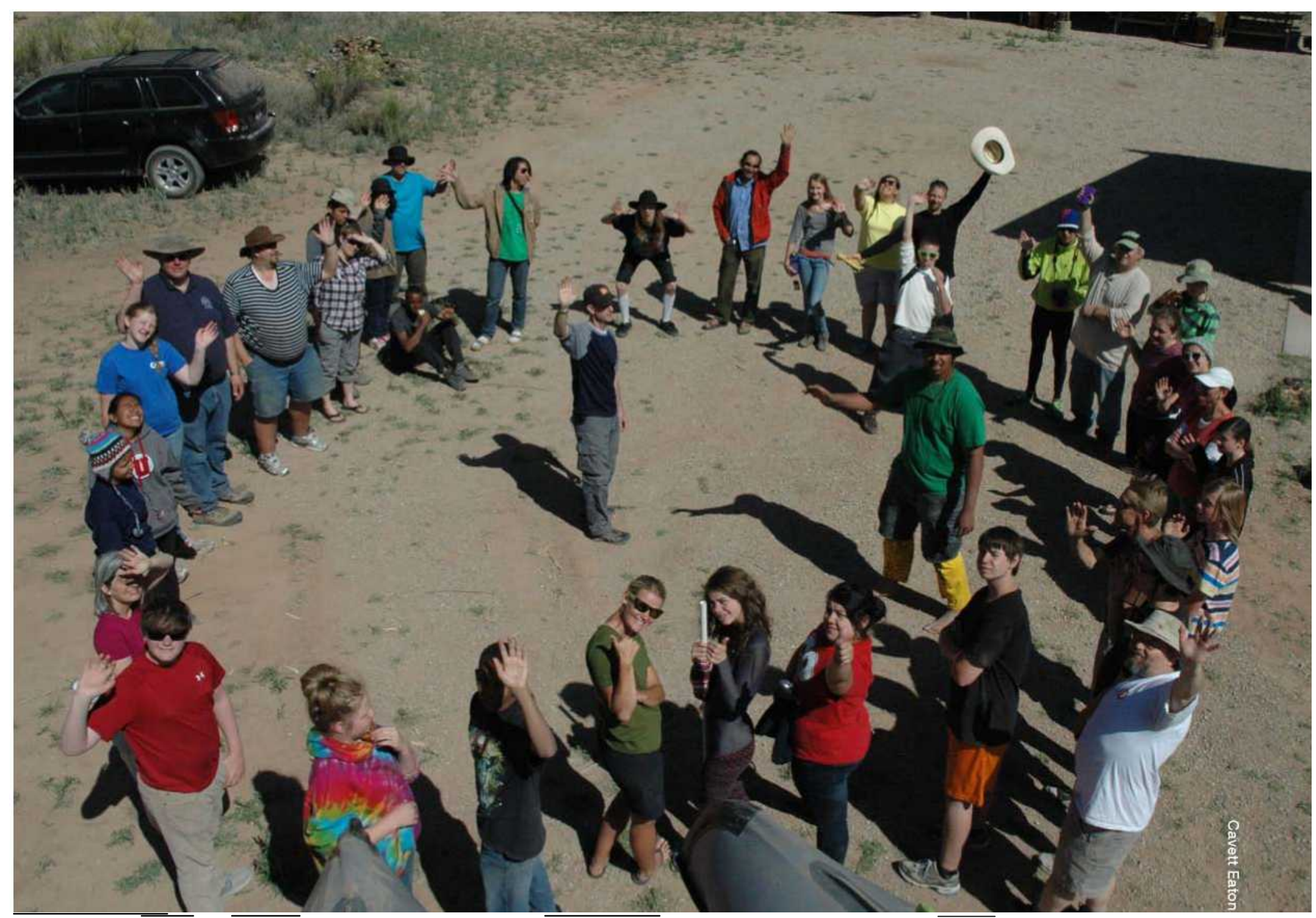

\section{Lessons Learned}

There are two powerful lessons to be learned from Eaton's nontraditional physical education and health program. First, physical education requirements can be met in a variety of ways. Second, the benefits from a program like Eaton's extend well beyond the physical realm. Based on his success, more physical educators are encouraged to consider incorporating "nontraditional" recreationbased programming into their curricula. Moving beyond ball sports into lifelong leisure pursuits, venturing beyond the brick and mortar of a school's physical plant into nature, and offering youth opportunities for exploration, wonder, questioning, problem solving, decision making, and team building can do much more for the whole child than sport skill instruction or physical conditioning alone.

For teachers and administrators who believe in educating the whole child and in the health benefits of lifelong leisure pursuits, Eaton's program is proving to be a highly successful model for teaching physical education. With a can-do attitude and a willingness to work collaboratively, today's public school teachers and administrators can play a leading role in generating a happier and healthier student body that will someday metamorphose into a happier and healthier citizenry.

\section{References}

Carson, R. (1998). The sense of wonder. New York, NY: Harper Collins.

Crompton, J. (2000). Sharing space: Schools can serve as recreation facilities to benefit the community. Parks \& Recreation, 34(5), 100-108.

Dustin, D., McKenney, A., Hibbler, D., \& Blitzer, L. (2004). Thinking outside the box: Placing park and recreation professionals in K-12 schools. Journal of Physical Education, Recreation \& Dance, 75(1), 51-54.

Kolb, D. A. (1984). Experiential learning: Experience as the source of learning and development. Englewood Cliffs, NJ: Prentice Hall.

Louv, R. (2006). The last child in the woods: Saving children from naturedeficit disorder. Chapel Hill, NC: Algonquin.

Ratey, J. (2008). Spark: The revolutionary new science of exercise and the brain. New York, NY: Little, Brown.

Schreffler, M. (2002). Lessening the risk for children and youth: A cooperative middle school after-care program. In A. McKenney \& D. Hibbler (Eds.), Serving youth-at-risk: Parks, recreation and the public school (pp. 13-16). Miami: Center for Urban Education \& Innovation, Florida International University.

Society of Health and Physical Educators. (2014). National standards \& grade-level outcomes for K-12 physical education. Champaign, IL: Human Kinetics. 